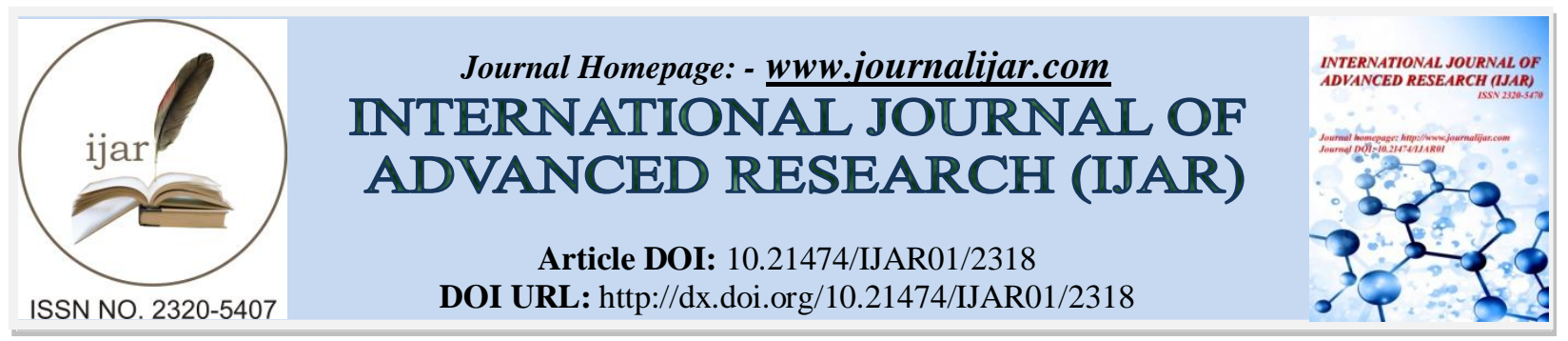

RESEARCH ARTICLE

\title{
EVALUATION THE VARIOUS CHARACTERISTICS OF THE WATER BY USING IONIZATION DEVICE.
}

Sulaiman Dawood Jasim.

Northern Technical University, Technical Institute of Mosul, Iraq.

\section{Manuscript Info}

Manuscript History

Received: 29 September 2016

Final Accepted: 30 October 2016

Published: November 2016

Key words:-

Water, Renewable, sustainable development, Ionization device. Iraq

\section{Abstract}

Water is a renewable natural resource which forming $75 \%$ of the planet and represents $80 \%$ of organism's bodies so require sustainable water development to maintain it from depletion and pollution also to improve physical, chemical and biological properties. That the potable water formed on surface level of planet $1.5-2 \%$. This study came to improve certain qualities of different types of water, for this aim been manufacturing water ionization device where ionize the water to acidic and alkaline. Different types of water were treated by device, had been tested different samples of ; drinking, mineral and magnetic water where checked properties of those samples, found the changes of the value of acidic, turbidity and electrical conductivity as explained in the tables (1-12), had been observed a decrease in PH value when using magnetic water from 9.6 to 4.6 , when used mineral water had been decreased $\mathrm{PH}$ values ranging from 4.6 to 6.9 , while hadn't noticed any change in $\mathrm{pH}$ values when using mineral water. Never gets changed in a characteristic turbidity when using magnetic water, changes observed when using mineral water in turbidity values ranging between 1.5 to $2.3 \mathrm{NTU}$ in the cathode and ranged from 0.9 to 2.9 in the anode. The electrical conductivity (Ec) in all water types' tests indicate that the water was appropriates for potable and irrigation which ranging the Ec from 100 to 350 US.

Copy Right, IJAR, 2016,. All rights reserved.

\section{Introduction:-}

Water was essential element for life where $75-80 \%$ of the human and organism's bodies be composed of water. In the contemporary world the water resources suffered more challenges such as depletion and pollution by the reason of irrational consumption of water, where increased; acidic water, salinity, drought, desertification...etc[1][2]. Which these factors reflected in negative form on human, other organism's life and biosphere. So require the attention for this resource to maintain its balance and improve their physical, chemical and biological properties by Eco-friendly systems manner as a green technical [3][4]. Moreover, water forms $90 \%$ of the components of blood. Intuitively, if most of the human body is water, why not pick its best benefits for the body? Alkaline ionized water is the only one in the contemporary world that is able to remove the real causes of our diseases particularly severe diseases such as hypertension, diabetes, cancer, gout and joint pain ... etc., without even side effects, why? Because the secret of its components lies in the presence of acidic toxic to expel waste from the body in addition to enormous amount of oxygen (160 to 200) two folds of the oxygen found in other water, which increases the energy and

Corresponding Author:- Sulaiman dawood jasim.

Address:- Northern Technical University, Technical Institute of Mosul, Iraq. 
activity of others ordinary body, in addition to a huge amount of antioxidants oxidation to balance free radicals.[5][6].

\section{Materials and Methods:-}

This research was conducted in Technical Institute of Mosul / Iraq in labor of watery resources by using ionization device which manufactured by local manner which consists of three elements;

1. Slot ingress of water from the source and which are fitted with a valve prevents ingress of water when filled ionization chamber.

2. Ionization room is containing two chambers separated by a bottom and joint from the top, in every room there is one cylinder a wire copper around it, could not get a platinum wire because it is very expensive, there are two faucets, each faucet connected to chamber for the exit of the water of both types of acidic and alkalized faucet.

3. Source of energy have a charger device provides electrical effort of 12 volts, as shown in Figure 1.It works when ionization chamber is filled with water from a slot associated with the source of water to a certain limit, the device operates for two hours after tying poles charger provide 12 volt. Water is ionized negative ions that gather around the positive pole in the ionization chamber, positive ions accumulate in a second chamber which is acidic ions; samples are taken every half an hour for the two operating hours for each type of water. The samples are taken to open the tap at the bottom of two rooms and packed in containers for the purpose of testing and benefiting from it. The device is run for two hours each experiment, with five types of water testing methods (plain water, mineral water, distilled water, magnetized water degree in 1000 gauss, magnetized water degree in 2000 gauss), and then took the samples were tested in the laboratory modern to checking the $\mathrm{pH}$ values, the values of electrical conductivity, turbidity in checking from the device water samples and laboratory tests showed good values in all the experiments that have been made, that access to alkaline water these ratios a seen in tables (2-11), this consider a scientific success because its great importance to the multiple uses including humanly and agricultural.

\section{Discussion and Results:-}

For the water a great importance in life of organisms so require improving its physical, chemical and biological properties, therefore conducted this research to contribute to service this bio resource [7][8]. Where spring water is considered purely alkaline water which contains alkaline minerals beside it is very rich in oxygen and antioxidants (electrons) which is similar to ionized alkaline water which is also produced by water ionized device and it is different from drinking water we consume because it lacks pure alkaline properties, antioxidants and oxygen excess. This what makes the natural spring water and ionized alkaline water highly effective in neutralizing and removing waste toxic acidic and free molecules from the human body which is resulting from production of bio-energy and metabolism, which are also the main causes of premature aging and adult diseases especially, lethal. [9][10], Secondly; acidic water this type of water is also known as sulfurous water. It has a very distinctive smell which is found in some regions of the world and contains oxidizing elements fatal to bacteria and parasites. To get rid of dermatology diseases, one may take a bath and this type of water is also similar to the acidic water produced by the ionized water. Thirdly: Mountain Spring Water .After conducting a number of field experiments on the mountain water springs, The American Scientist, SANG WANG and professor of chemistry and biochemistry, Professor EDWARD DRATS in Montana University of America, said that this type of water is considered alkaline water but free of acidic elements and rich in antioxidant minerals (electrons) and the amount of excess oxygen and usefulness of this ratio high in oxygen enables the body to carry out all the vital functions efficiently. It also works on easing function of the heart and lungs and it encourages deep sleep, kills cancer cells and prevent their spread, and this is what makes the natural spring water and alkaline ionized water with extraordinary ability in the equation and the removing power of acidic waste toxic free and molecules of the human body resulting from the metabolism and the production of bio-energy process, and this type of water is exactly ionized alkaline water produced by the water ionized device. The main aim of the current study is manufacturing a device to ionize water in addition to studying different samples of water ionization process in terms of turbidity and sterilization .Clear in lab results when using a strongly magnetized water ( 1000 ) gauss, the value of ( $\mathrm{PH}$ ) decreased from 9.6 to 4.6 and this makes the water more alkaline than magnetization water (Figure 5). When using magnetized water vigorously (2000) gauss we do not get a clear change or a significant drop in the value of the PH ( Fig. 11 ), which the values can be seen in the tables(2), (3 ), (4) and (5 ).But when using mineral water, low PH values had been obtained more than in the magnetized water (Fig. 17), decreased the value of $\mathrm{PH}$ with the passage of the ionization time until it reached after two hours to (5.9) in the anode, ranging values between (2.6 to 9.5) and this can be seen in the two tables (6) and (7). The same value did not change while using distilled water (Figs. 20 and 23), a marked change with the time of 
ionization also in tables (8) and (9). While the obtained values (PH) good using ordinary water (Figs. 26 and 29) as it fell values $(\mathrm{PH})$ with the passage of the ionization time even seemed ranging between (4.6 to 9.6), these results are good when compared to local and international standards for drinking water as shown in the table (10) and (11). We did not get good values for turbidity values permitted according to international standards in the table (1) when the ionization of magnetized water in both degrees magnetization strongly ( 2000-1000) gauss ( Figures 3,6,9,12) . While the results were stunning in the ionization of mineral water (Figs. 15 and 18), where it was to get the lowest rate turbidity ranging between (2.3 -1.5 NTU) in the Anode and between (0.9 - $2.9 \mathrm{NTU})$ in Cathode, tables (6) and ( 7) .The same applies when using distilled water ( Figs. 20 and 24), where it was to obtain values for turbidity ranging between (9.9 -3.1 NTU) in the anode and values ranging between (1.6 -1.0 NTU) at the cathode as shown in Tables (8) and (9). The turbidity values in plain water ranges from between (8.95 -6.64 NTU) (Figs. 27 and 30) at the cathode, while the values ranged from (18.4 -13.6 NTU) at the anode, and are considered good values in comparison with local and international standards, these values even considered very pure and drinkable and useful for human who suffer from the effects of contaminated water or pain in the digestive and urinary tract, as in the two tables (10), (11) . the electrical conductivity ( EC ) in all the appropriate tests for drinking and irrigation most of the plants compared with the table (12), with values ranging between (350 -100 US)

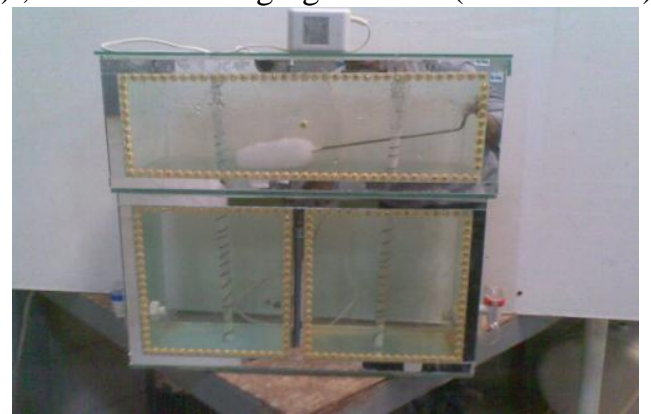

Figure 1:- Water Ionization device.

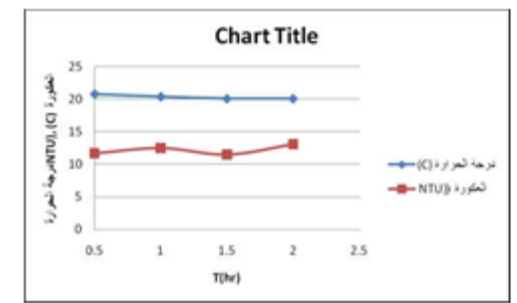

Figure 3. The relation ship between the ionization time, temperature and turbidity of the water magnetized by ( 1000 ) gauss resulting from the negative pole to water ionization

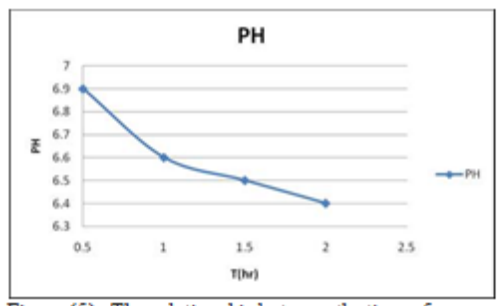

Figure (5): The relations hip between the time of ionization and the PH of the water magnetized by ( 1000$)$ gauss resulting from the positive pole to ionize water

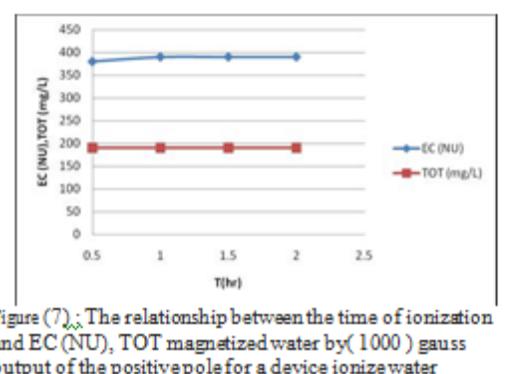

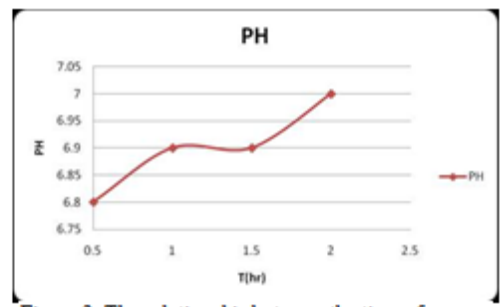

Figure 2: The relationship between the time of ionization and the $\mathrm{PH}$ of the water magnetized by ( 1000 ) gaus 5 resulting from the negative pole to water

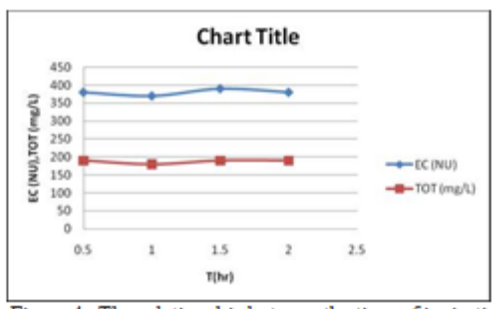

Figure 4: The relation ship between the time of ionization and $\mathrm{EC}(\mathrm{NU})$, TOT magnetized water by ( 1000 ) gaus 5 output of the CRT device to ionize water

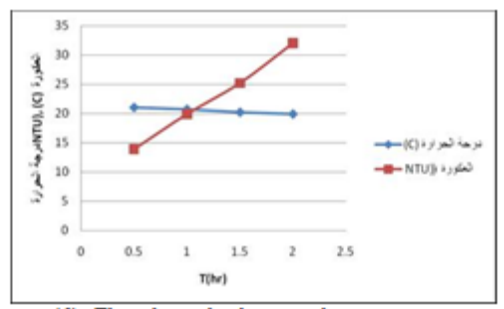

Figure (6): The relationship between the ionization time, temperature and turbidity of the water magnetized by ( 1000 ) gaus 5 resulting from the positive pole to ionize water 


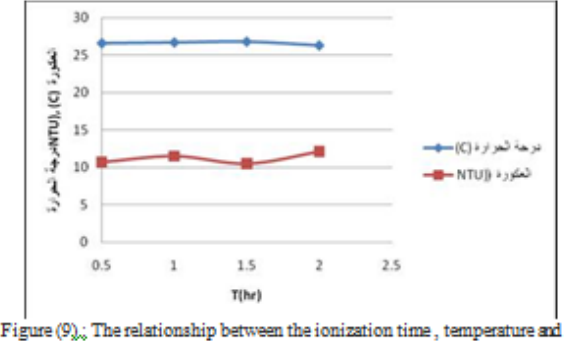
Figure (9): The relationship between the ionization time, temperature and negative pole to ionize water system

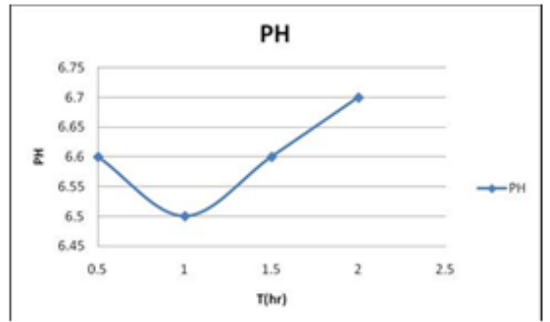

Figure(11): The relationship between the time of ionization and the $\mathrm{PH}$ of the water magnetized by (2000) gauss resulting from the positive electrode to ionize water

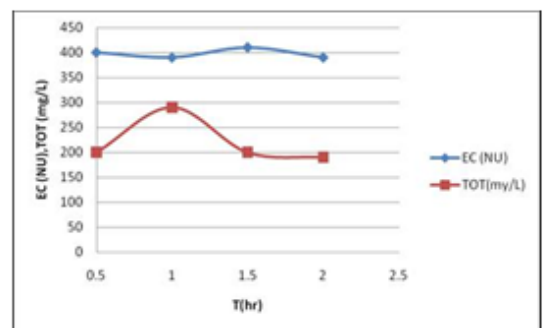

Figure (13): The relationship between the time of ionization and EC (NU), TOT) (magnetized water by (2000) gauss output of the positive pole for a device ionize water

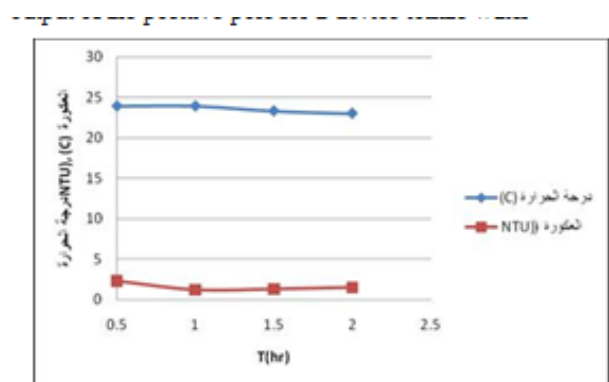

Figure(15): The relationship between the ionization time, temperature and turbidity of mineral water resulting from the negative pole to ionize water system

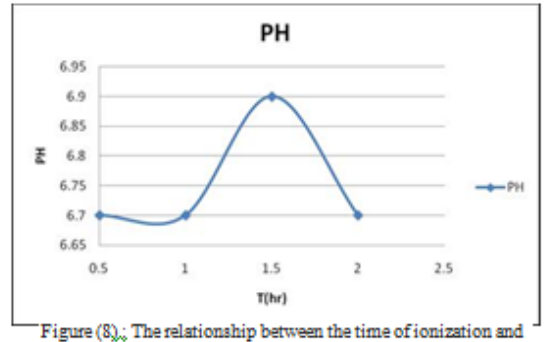

Figure (8): The relationship between the time of ionization and
the PH of the water magnetizad by (2000) gasus resulting from the negative pole to ionize water system

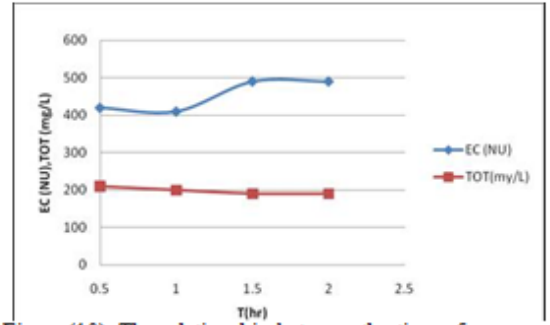

Figure(10): The relationship between the time of ionization and EC (NU), TOT) (magnetized water by (2000) gauss output of the CRT device to ionize water

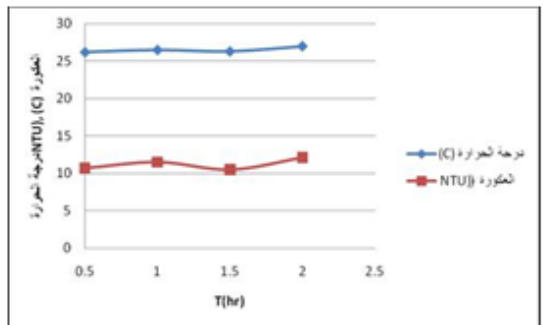

Figure (12): The relationship between the ionization time, temperature and turbidity of the water magnetized by $(2000)$ gauss resulting from the positive pole to ionize water system

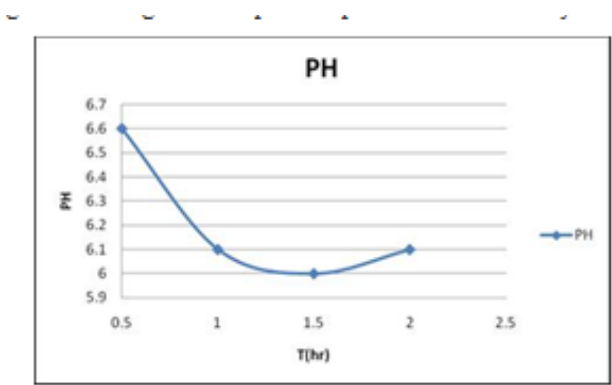

Figure(14): The relationship between the time of ionization and the $\mathrm{PH}$ mineral water resulting from the negative pole to ionize water system 


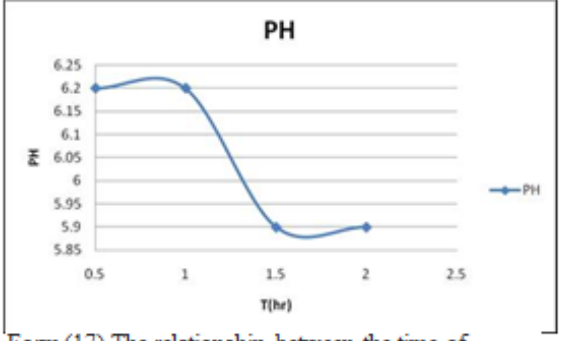

Form (17) The relationship between the time of ionization and the PH mineral water resulting from the positive pole to ionize water system

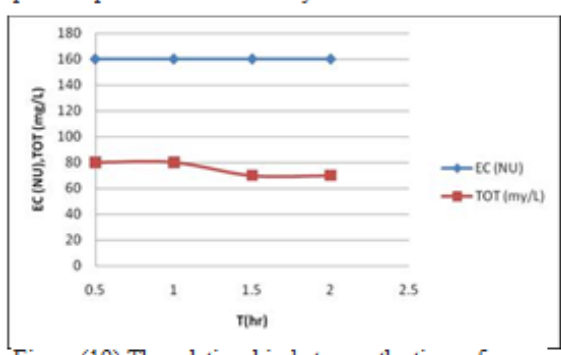

Figure(19) The relationship between the time of ionization and EC (NU), TOT) ( mineral water resulting from the positive pole to ionize water system

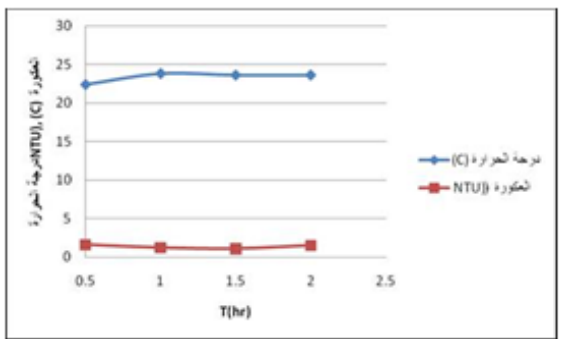

Figure (21) The relationship between the ionization time, temperature and turbidity of the water distilled resulting from the negative pole to ionize water

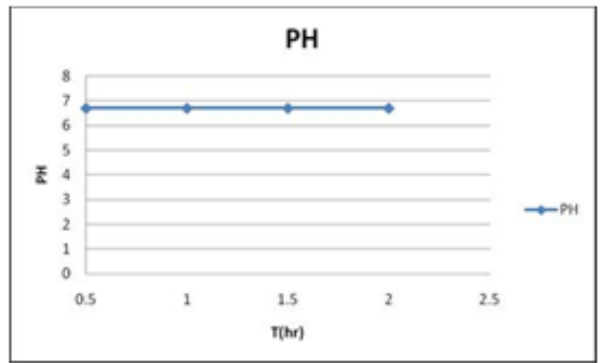

Figure (23) The relationship between the time of ionization and the $\mathrm{PH}$ of the water resulting from the positive electrode to ionize a distilled water

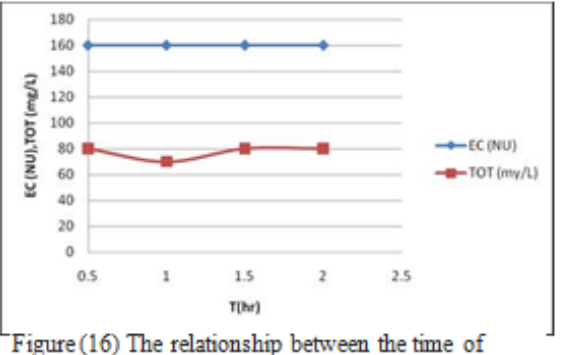

Figure(16) The relationship between the time of ionization and EC (NU), TOT) (mineral water resulting from the cathode to ionize water system

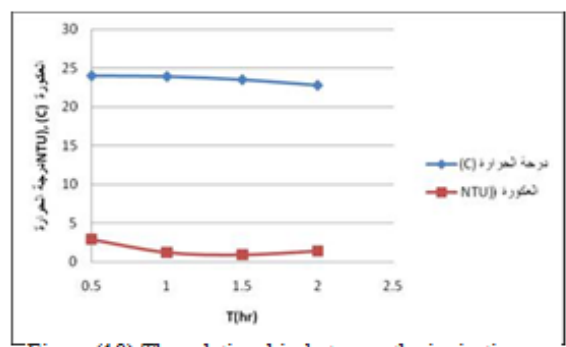

Figure (18) The relationship between the ionization time, temperature and turbidity of mineral water resulting from the positive pole to ionize water system

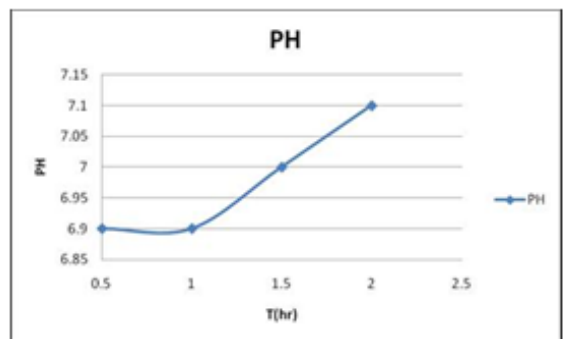

Figure (20) The relationship between the time of ionization and the $\mathrm{PH}$ of distilled water resulting from the cathode to ionize water system

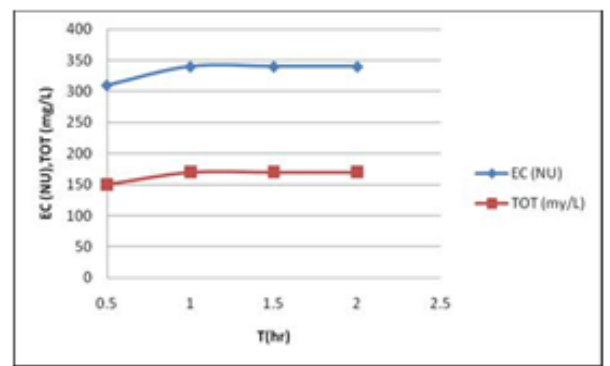

Form (22): The relationship between the time of ionization and $\mathrm{EC}(\mathrm{NU})$, TOT) (distilled water resulting from the cathode to ionize water system 

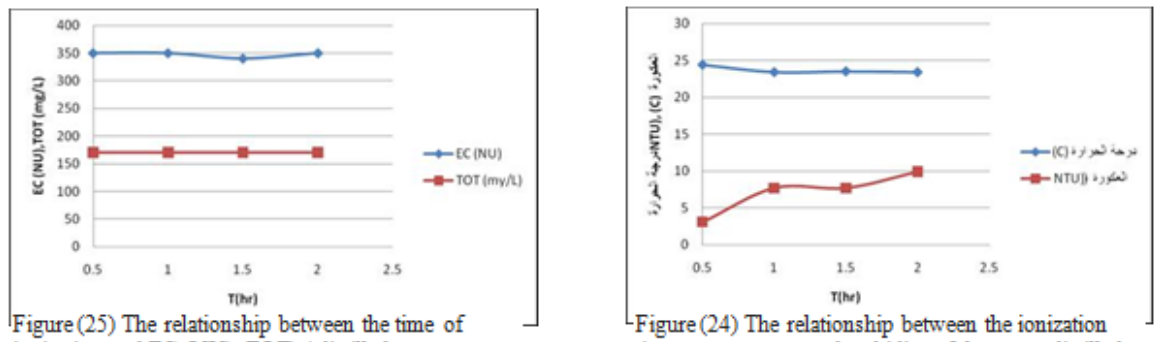

ionization and EC (NU), TOT) (distilled water

resulting from the positive pole to ionize water system

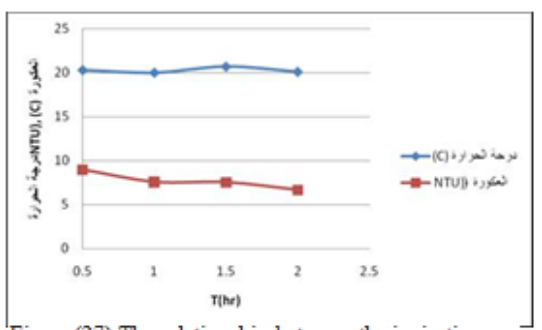

time, temperature and turbidity of the water distilled resulting from the positive pole to ionize water system

Figure (27) The relationship between the ionization

time, temperature and turbidity normal water

resulting from the cathode to ionize water system

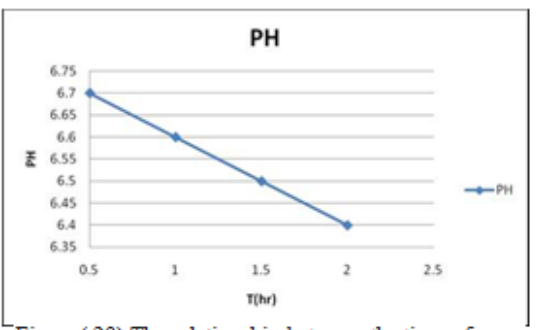

Figure (29) The relationship between the time of ionization and the $\mathrm{PH}$ normal water resulting from the positive pole to ionize water system

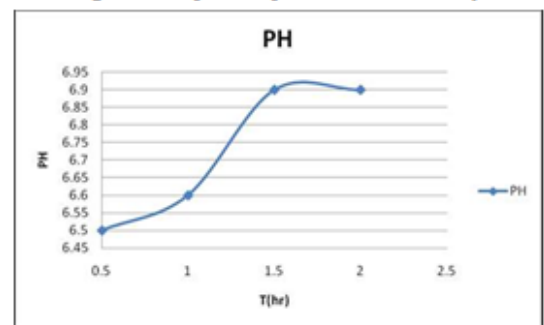

Figure (26): The relationship between the time of ionization and the PH nomal water resulting from the cathode to ionize water system

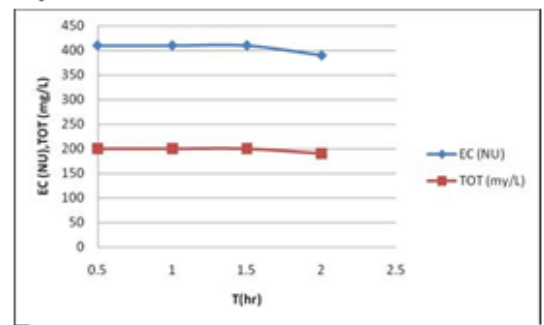

Figure (28)The relationship between the time of ionization and $\mathrm{EC}(\mathrm{NU}), \mathrm{TOT}$ ) (normal water resulting from the cathode to ionize water system

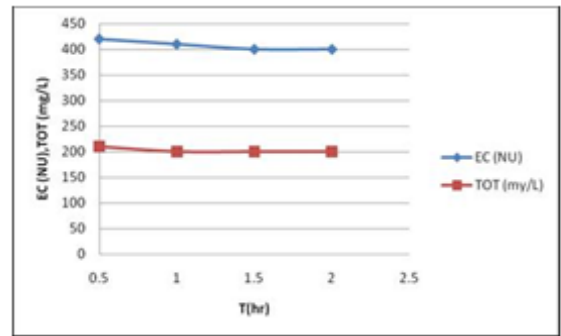

Figure (31)The relationship between the time of ionization and EC (NU), TOT) (normal water resulting from the positive pole to ionize water system

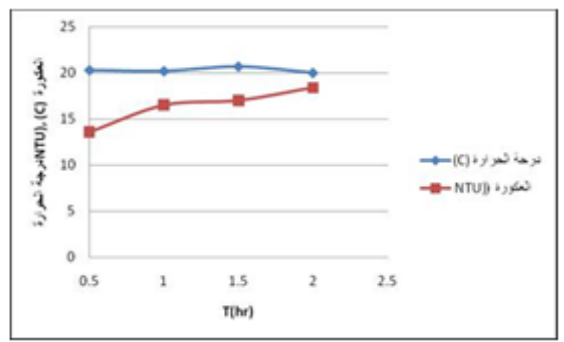

Figure (30) The relationship between the ionization time, temperature and turbidity normal water resulting from the positive pole to ionize water system

Table 1:- Specifications of drinking water for household uses

\begin{tabular}{|c|c|c|c|}
\hline $\begin{array}{l}\text { Limits allowed according to the } \\
\text { specifications of the World Health } \\
\text { Organization }\end{array}$ & $\begin{array}{c}\text { Limits allowed according to the Iraqi } \\
\text { specifications for the year } 1986\end{array}$ & $\begin{array}{c}\text { Measurement } \\
\text { Unit }\end{array}$ & Substance \\
\hline $6.5-8.5$ & $6.5-8.5$ & & PH \\
\hline 5 & Less than 10 & N.T.U & turbidity \\
\hline
\end{tabular}

Table 2:- testing the water of magnetic force of 1000 gauss resulting from the device .

\begin{tabular}{|c|c|c|c|c|c|}
\hline (NTU) turbidity & TOT (mg/L) & EC (US) & (C) Temperature & PH & T(hr) \\
\hline 11.7 & 190 & 380 & 20.8 & 6.8 & 0.5 \\
\hline 12.5 & 180 & 370 & 20.4 & 6.9 & 1.0 \\
\hline 11.5 & 190 & 390 & 20.1 & 6.9 & 1.5 \\
\hline 13.1 & 190 & 380 & 20.1 & 7.0 & 2.0 \\
\hline
\end{tabular}


Table 3:- testing the water of magnetic force of 1000 gauss resulting from the positive pole to ionize water system

\begin{tabular}{|c|c|c|c|c|c|}
\hline (NTU)turbidity & TOT(my/L) & EC (US) & $\left.\mathbf{( C}^{\mathbf{0}}\right)$ Temperature & PH & T(hr) \\
\hline 10.7 & 210 & 420 & 26.6 & 6.7 & 0.5 \\
\hline 11.5 & 200 & 410 & 26.7 & 6.7 & 1.0 \\
\hline 10.5 & 190 & 490 & 26.8 & 6.9 & 1.5 \\
\hline 12.1 & 190 & 490 & 26.3 & 6.7 & 2.0 \\
\hline
\end{tabular}

Table 4:- testing the water magnetized by (2000) gauss resulting from the negative pole to ionize water system

\begin{tabular}{|c|c|c|c|c|c|}
\hline (NTU) turbidity & TOT $(\mathbf{m g} / \mathbf{L})$ & EC $(\mathbf{U S})$ & $\left.\mathbf{( C}^{\mathbf{0}}\right)$ Temperature & PH & T(hr) \\
\hline 13.9 & 190 & 380 & 21.0 & 6.9 & 0.5 \\
\hline 19.9 & 190 & 390 & 20.7 & 6.6 & 1.0 \\
\hline 25.2 & 190 & 390 & 20.2 & 6.5 & 1.5 \\
\hline 32.0 & 190 & 390 & 19.9 & 6.4 & 2.0 \\
\hline
\end{tabular}

Table 5:- testing the water magnetized by (2000) gauss resulting from the positive pole to ionize water system.

\begin{tabular}{|l|l|l|l|l|l|}
\hline turbidity )NTU( & TOT $(\mathbf{m y} / \mathbf{L})$ & $\mathbf{E C}(\mathbf{U S})$ & $\left.\mathbf{C}^{\mathbf{0}}\right)$ Temperature & PH & T(hr) \\
\hline 10.7 & 200 & 400 & 26.2 & 6.6 & 0.5 \\
\hline 11.5 & 290 & 390 & 26.5 & 6.5 & 1.0 \\
\hline 10.5 & 200 & 410 & 26.3 & 6.6 & 1.5 \\
\hline 12.1 & 190 & 390 & 27.0 & 6.7 & 2.0 \\
\hline
\end{tabular}

Table 6:- mineral water tests resulting from the negative pole to ionize water system.

\begin{tabular}{|l|l|l|l|l|l|}
\hline turbidity $)$ NTU( & TOT $(\mathbf{m y} / \mathbf{L})$ & $\mathbf{E C}(\mathbf{U S})$ & $\left(\mathbf{C}^{0}\right)$ Temperature & PH & T(hr) \\
\hline 2.3 & 80 & 160 & 23.9 & 6.6 & 0.5 \\
\hline 1.2 & 70 & 160 & 23.9 & 6.1 & 1.0 \\
\hline 1.3 & 80 & 160 & 23.3 & 6.0 & 1.5 \\
\hline 1.5 & 80 & 160 & 23.0 & 6.1 & 2.0 \\
\hline
\end{tabular}

Table 7:- Tests of mineral water resulting from the positive pole to ionize water system.

\begin{tabular}{|l|l|l|l|l|l|}
\hline turbidity $)$ NTU( & TOT $(\mathbf{m y} / \mathbf{L})$ & EC $(\mathbf{U S})$ & $\left(\mathbf{C}^{\mathbf{0}}\right)$ Temperature & PH & T(hr) \\
\hline 2.9 & 80 & 160 & 24.0 & 6.2 & 0.5 \\
\hline 1.2 & 80 & 160 & 23.9 & 6.2 & 1.0 \\
\hline 0.9 & 70 & 160 & 23.5 & 5.9 & 1.5 \\
\hline 1.4 & 70 & 160 & 22.8 & 5.9 & 2.0 \\
\hline
\end{tabular}

Table 8:- testing distilled water output from the cathode to ionize water system.

\begin{tabular}{|l|l|l|l|l|l|}
\hline turbidity )NTU( & TOT $(\mathbf{m y} / \mathbf{L})$ & $\mathbf{E C}(\mathbf{U S})$ & $\left(\mathbf{C}^{0}\right)$ Temperature & PH & T(hr) \\
\hline 1.6 & 150 & 310 & 22.4 & 6.9 & 0.5 \\
\hline 1.2 & 170 & 340 & 23.8 & 6.9 & 1.0 \\
\hline 1.08 & 170 & 340 & 23.6 & 7.0 & 1.5 \\
\hline 1.51 & 170 & 340 & 23.6 & 7.1 & 2.0 \\
\hline
\end{tabular}

Table 9:- testing distilled water resulting from the positive pole to ionize water system .

\begin{tabular}{|l|l|l|l|l|l|}
\hline turbidity )NTU( & TOT $(\mathbf{m y} / \mathbf{L})$ & $\mathbf{E C}(\mathbf{U S})$ & $\left(\mathbf{C}^{0}\right)$ Temperature & PH & T(hr) \\
\hline 3.1 & 170 & 350 & 24.4 & 6.7 & 0.5 \\
\hline 7.7 & 170 & 350 & 23.4 & 6.7 & 1.0 \\
\hline 7.7 & 170 & 340 & 23.5 & 6.7 & 1.5 \\
\hline 9.9 & 170 & 350 & 23.4 & 6.7 & 2.0 \\
\hline
\end{tabular}


Table 10:- Testing normal water resulting from the CRT device to ionize water.

\begin{tabular}{|l|l|l|l|l|l|}
\hline turbidity )NTU( & TOT $(\mathbf{m y} / \mathbf{L})$ & EC (US) & $\left.\mathbf{C C}^{\mathbf{0}}\right)$ Temperature & PH & T(hr) \\
\hline 8.95 & 200 & 410 & 20.3 & 6.9 & 0.5 \\
\hline 7.56 & 200 & 410 & 20.0 & 6.6 & 1.0 \\
\hline 7.52 & 200 & 410 & 20.7 & 6.9 & 1.5 \\
\hline 6.64 & 190 & 390 & 20.1 & 6.9 & 2.0 \\
\hline
\end{tabular}

Table 11:- Testing normal water resulting from the positive pole to ionize water system.

\begin{tabular}{|l|l|l|l|l|l|}
\hline turbidity )NTU( & TOT (my/L) & EC (US) & $\left.\mathbf{( C}^{\mathbf{0}}\right)$ Temperature & PH & T(hr) \\
\hline 13.6 & 210 & 420 & 20.3 & 6.7 & 0.5 \\
\hline 16.5 & 200 & 410 & 20.2 & 6.6 & 1.0 \\
\hline 17 & 200 & 400 & 20.7 & 6.5 & 1.5 \\
\hline 18.4 & 200 & 400 & 20.0 & 6.4 & 2.0 \\
\hline
\end{tabular}

Table 12:- international specifications for electrical conductivity (E.C) by the US Salinity.

\begin{tabular}{|l|l|l|}
\hline Code & E.C Symbol & Type \\
\hline C1 & $0.250-0.100$ & Low- salinity water \\
\hline C2 & $0.750-0.250$ & Medium- salinity water \\
\hline C3 & $2.250-0.750$ & High - salinity water \\
\hline C4 & $5.000-2.250$ & Very High - salinity water \\
\hline
\end{tabular}

\section{Conclusion and Recommendation:-}

1.

2.

3.

Alkaline value which

4. best use of water for human.

5. The values of electrical conductivity (EC) using drinking water better ionized and useful for most plants.

\section{References:-}

1 .

M.Aliyas ,2011,A study some quality properties of the sulfur water in sprigs water ,Iraq ,Nineveh province ,journal of Building Science ,Kharkov state University, Ukraine ,No:65, ,P.,339-344.

2. L.D.Patsuk,2011,Evaluation the quality of drinking water in Nineveh province ,Scientific journal ,University of Agriculture ,Sumy,Ukraine,No:8(23).

3. ALIYAS .N.I, 2012,A study quality underground water in some regions of Nineveh province, journal of building Science, Kharkov state University, Ukraine No:,67,P.,240.

4. Marc Henry 1,* and Jacques Chambron 2 (2013) Physico-Chemical, Biological and Therapeutic Characteristics of Electrolyzed Reduced Alkaline Water (ERAW) Water, 5, 2094-2115; doi:10.3390/w5042094.

5. 5-H. Assaf, Dr. M. S. Al-Masri(2007), Sources of Groundwater Contamination,Department of Protection and Safety, Atomic Energy Commission of Syria,Damascus P.O.Box 6091, Syria

6. Guy Fipps, 2003. Irrigation water quality Standards and Salinity Management. Texas A \& E AGRILIFE extension B-1667.

7. Millon Firman 1965. Quality of water for irrigation. Fact Sheet. Cooperative Extension in Agriculture and Home Economic, College of Agric. Univ. of California and USDA 3p.

8. Ayers, R.S. and D.W. Westoct 1994. Water quality for agriculture. FAO Corporae Document Repository. FAO irrigation and drainge paper.

9. Christopher Vasey N.D (2004), The Acid-Alkaline Diet for Optimum Health: Restore Your Health by Creating Balance in Your Diet Paperback - January 31, 2004.

10. http://lamsetshefa.syriaforums.net/t111-topic. 